IMECE2005-82519

\title{
FATIGUE PERFORMANCE OF AAR CLASS A RAILROAD WHEEL STEEL AT AMBIENT AND ELEVATED TEMPERATURES
}

\author{
Fraser J. McMaster \\ Southwest Research Institute \\ Materials Engineering Department \\ P.O. Drawer 28510, San Antonio, \\ Texas 78228-0510 USA \\ 210.522.2017 210.522.6965 \\ fmcmaster@swri.org
}

\author{
Guadalupe B. Robledo \\ Southwest Research Institute \\ Materials Engineering Department \\ P.O. Drawer 28510, San Antonio, \\ Texas 78228-0510 USA \\ 210.522.2456 210.522.6965 \\ wally.robledo@swri.org
}

\author{
Jeffrey E. Gordon \\ U.S. Department of Transportation \\ Volpe Center, 55 Broadway \\ Kendall Square, Cambridge, \\ Massachusetts 02142 USA \\ 617.494.2303 617.494.3616 \\ gordonj@volpe.dot.gov
}

\section{ABSTRACT}

Classical stress-life (S-N) curves were developed for Association of American Railroads (AAR) Class A wheel steel with specimens removed from the rim area of an as-forged railcar wheel. The specimen geometry was a standard hourglass fatigue test specimen with a low stress concentration $\left(\mathrm{K}_{\mathrm{t}}\right)$ of 1.05. Fatigue testing was performed at stress ratios of -1.0 , $0.05,0.5$ and 0.7 . Testing was performed at ambient, $500^{\circ} \mathrm{F}$ and $1000^{\circ} \mathrm{F}$ using high current resistance or convection methods. Endurance limit data was obtained for all R-ratios, although for the $1000^{\circ} \mathrm{F}$ condition there did not appear to be a clear endurance limit transition. These endurance limit data were used to estimate the Sines parameters, A and $\alpha$.

Keywords: fatigue, wheel steel, cyclic life, S-N, life prediction

\section{NOMENCLATURE}

$\begin{array}{ll}\mathrm{A} & \text { Sines criteria material constant } \\ \mathrm{K}_{\mathrm{t}} & \text { stress concentration factor } \\ \mathrm{P}_{\mathrm{i}} & \text { principle stress amplitude } \\ \mathrm{R} & \text { load ratio, ratio of minimum to maximum load } \\ \mathrm{RA} & \text { reduction of area at failure } \\ \mathrm{S}_{\mathrm{i}} & \text { orthogonal mean stresses } \\ \mathrm{S}-\mathrm{N} & \text { stress-life } \\ f_{1} & \text { amplitude of reversed axial stress } \\ f_{1}^{\prime} & \text { amplitude of fluctuating stress causing failure } \\ \alpha & \text { Sines criteria material constant } \\ \varepsilon & \text { percent elongation at failure } \\ \sigma_{\max } & \text { maximum applied stress level } \\ \sigma_{\mathrm{UTS}} & \text { ultimate tensile strength } \\ \sigma_{\mathrm{YS}} & 0.2 \% \text { yield strength }\end{array}$

\section{INTRODUCTION}

The American Public Transportation Association (APTA) Passenger Rail Equipment Safety Standards Committee on wheel design is working toward the development of fitness-forservice design criteria for railroad wheels used in transit and passenger applications. The existing standard (namely, AAR Standard S-660 [1]) deals primarily with wheel designs for North American freight applications. The APTA committee is presently seeking to develop an equivalent standard for passenger and transit wheels.

However, the committee faces two fundamental problems. The first involves accounting for the multidimensional state of stress in the wheels and the second concerns the absence of any fatigue test data for wheel steels. Two methods for accounting for the complex stress state involve using the Sines criterion [2] or alternatively the Societé Nationale des Chemins de Fer (SNCF) criterion [3].

Although prior to this program the extent of S-N data was limited for this material, 92 fatigue tests were performed herein to characterize the baseline material response. The service loading conditions that forged wheels are subjected to include those due to wheel-on-rail contact as well as thermal loads from frictional heating during on-tread braking. Studies at the Volpe National Transportation Systems Center [4] have shown that the wheel surface temperatures can reach $1000^{\circ} \mathrm{F}$ during braking.

The purpose of this program is to determine the fatigue properties for Class A wheel steel. Previous testing has focused on the fatigue performance of a Class B wheel steel [5]. Where possible, the test results will be further interpreted in the context of the Sines criterion. 


\section{MATERIAL AND EXPERIMENTAL METHODS}

The AAR Class A wheel steel required for testing was supplied from two railroad wheels, sectioned into eight pieces per wheel. Specimens for tensile, chemical composition, and fatigue tests were extracted from each of the railroad wheels, focusing on the rim area as shown in Fig. 1. The two wheels were produced in February 2003 from steel heat P9871 (Standard Steel, Burnham, PA). The basic specimen geometries for mechanical testing generally conformed to the relevant ASTM specification [6], namely E08 and E466 for tensile and fatigue testing, respectively.

The tensile test specimens were machined into secondsubsize specimens with gage length of 1 inch and a gage diameter of 0.250 inch. Second-subsize specimens were used to enable a larger number of specimens to be extracted from the wheel sections, as well as insuring that the gage section was machined as close to the rolling contact surface as possible. The tensile properties were determined only in the circumferential orientation for the railroad wheels since this was the most relevant orientation for the fatigue specimens. The drawing of the fatigue specimen geometry is shown in Fig. 2.

Chemical analysis was performed on each of the two railroad wheels to provide verification that the material was within the specification for AAR M107/208 Class A steel. Analysis was performed in accordance with the standard ASTM test specifications [7,8].

Fatigue testing was performed at four different R-ratios including $\mathrm{R}=-1.0,0.05,0.5$, and 0.7 . The testing at $\mathrm{R}=-1.0$ and $R=0.05$ included sufficient specimens to generate the complete S-N curve. However, the testing at the other higher $\mathrm{R}$-ratio conditions, $\mathrm{R}=0.5$ and $\mathrm{R}=0.7$, included fewer specimens, so as to nominally determine the endurance limit. The fatigue testing was performed in the Southwest Research Institute (SwRI) Solid and Fracture Mechanics Laboratory using two closed-loop, servo-hydraulic test frames, with hightemperature furnaces required for the $500^{\circ} \mathrm{F}$ and $1000^{\circ} \mathrm{F}$ tests. A photograph of the high-temperature resistance test set-up for both the $500^{\circ} \mathrm{F}$ and $1000^{\circ} \mathrm{F}$ tests is shown in Fig. 3 . Furthermore, one other $500^{\circ} \mathrm{F}$ test frame was set up utilizing a convection heating clam-shell arrangement. Prior to starting each fatigue test, the controller set temperature was gradually increased to the desired level to avoid any temperature overshoot that may occur in the specimen during heating. Testing frequency was in the range of $10-25 \mathrm{~Hz}$, with test frequency dependent primarily on the R-ratio. All specimens were tested until failure (two-pieces) or until the runout level of 10 million cycles was reached.

\section{DATA ANALYSIS}

In 1955, Sines [2] reviewed the results of experiments on the effect of different combinations of tensile, compressive, and torsional mean and alternating stresses on fatigue life. He reported that the alternating of shear stresses seemed to cause fatigue failure. From this study he developed the relationship:

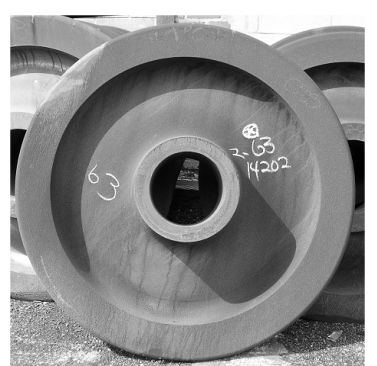

wheel 02-3-14202
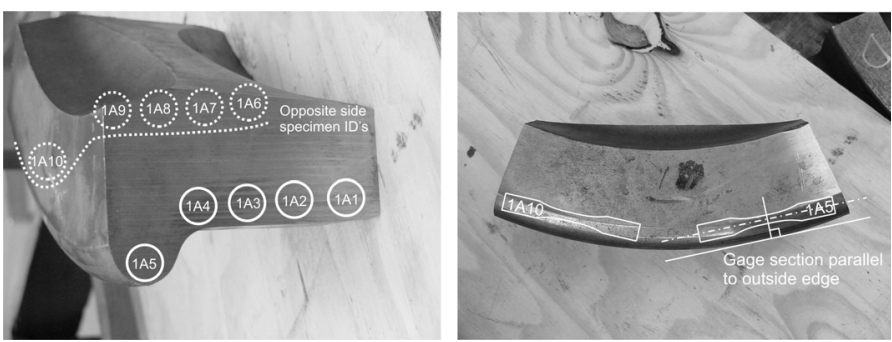

Figure 1

Schematic showing extraction of sections from the two railroad wheels

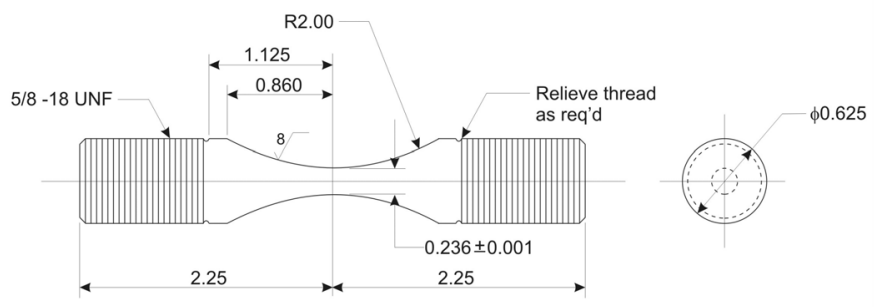

Figure 2

Design drawing for the hourglass fatigue specimen

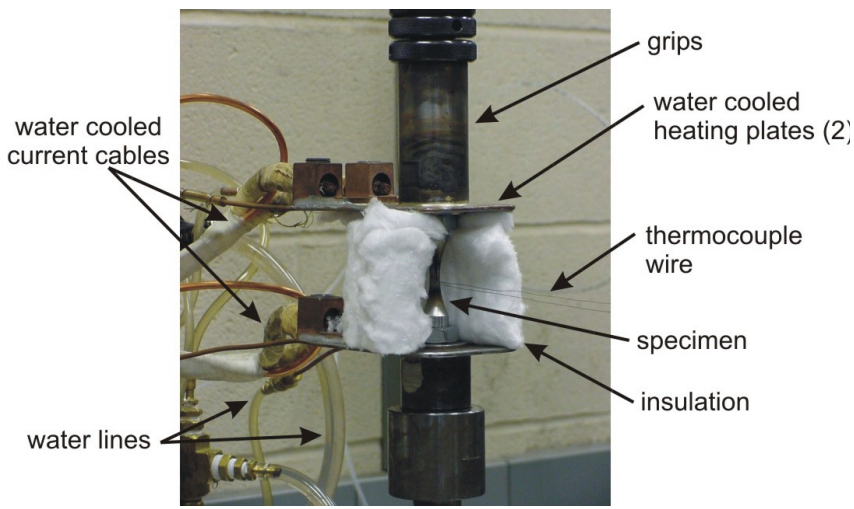

Figure 3

Detailed view of setup for $500^{\circ} \mathrm{F}$ and $1000^{\circ} \mathrm{F}$ high-temperature $\mathrm{S}-\mathrm{N}$ fatigue testing 
$\frac{1}{3} \sqrt{\left(P_{1}-P_{2}\right)^{2}+\left(P_{2}-P_{3}\right)^{2}+\left(P_{1}-P_{3}\right)^{2}}+\alpha\left(S_{x}+S_{y}+S_{z}\right) \leq A$

where

$$
\begin{aligned}
P_{1}, P_{2}, P_{3}= & \begin{array}{l}
\text { amplitudes of the alternating principal } \\
\text { stresses }
\end{array} \\
S_{x}, S_{y}, S_{z}= & \begin{array}{l}
\text { orthogonal (any coordinate system) mean } \\
\text { stresses }
\end{array} \\
= & \begin{array}{l}
\text { material constant proportional to reversed } \\
\text { fatigue strength }
\end{array} \\
= & \text { material constant, which gives variation of } \\
& \text { the permissible range of stress with static } \\
& \text { stress }
\end{aligned}
$$

$A$ and $\alpha$ are material properties for a given life level.

The constants $A$ and $\alpha$ may easily be determined from fatigue tests with a large R-ratio difference. For example, in a fully reversed uniaxial test, Eq. (1) is

$$
\frac{\sqrt{2}}{3} P_{1}=A \quad\left(P_{2}=P_{3}=S_{x}=S_{y}=S_{z}=0\right)
$$

Letting $P_{1}=f_{1}$ gives

$A=\frac{\sqrt{2}}{3} f_{1}$

where $f_{l}$ is the amplitude of reversed axial stress that would cause failure at the desired cyclic load. For 0 to $\sigma_{\max }$ loading $($ R-ratio $=0)$, Eq. (1) becomes

$S_{x}^{\prime}=P_{1}^{\prime} \quad\left(P_{2}^{\prime}=P_{3}^{\prime}=S_{y}^{\prime}=S_{z}^{\prime}=0\right)$

$\frac{\sqrt{2}}{3} P_{1}^{\prime}=A-\alpha P_{1}^{\prime}$

Letting $P_{1}^{\prime}=f_{1}^{\prime}$ yields

$\alpha=\frac{A}{P_{1}^{\prime}}-\frac{\sqrt{2}}{3}=\frac{\sqrt{2}}{3}\left(\frac{f_{1}}{f_{1}^{\prime}}-1\right)$

where $f_{1}^{\prime}$ is the amplitude of fluctuating stress that would cause failure at the same cyclic life as $f_{l}$. Thus $A$ and $\alpha$ are described in terms of stress amplitudes, $f_{1}$ and $f_{1}^{\prime}$.

\section{TEST RESULTS AND DISCUSSION}

\section{Material Characterization Results}

A summary of the chemical composition data is shown in Table 1, with the AAR Specification M-107/208 [9] allowable provided for comparison. The results given indicate that both the railroad wheel samples contained the required elements within the specified range, below the maximum, or above the minimum given.
Tensile test results for each of the three temperatures are shown in Table 2, with the room-temperature baseline tensile data for Class A wheel steel [1] also included for comparison. Room-temperature tensile yield stress $\left(\sigma_{\mathrm{YS}}\right)$ exceeded the minimum given by the AAR baseline, with the ultimate tensile strength $\left(\sigma_{\mathrm{UTS}}\right)$ also within the range specified.

Two observations are apparent from the test data given in Table 2. Firstly, a dramatic decrease in the ultimate tensile strength and yield stress occurred when testing at a temperature of $1000^{\circ} \mathrm{F}$, with a greater than 47 percent reduction in $\sigma_{\text {UTS }}$ and 36 percent reduction in $\sigma_{Y s}$. Secondly, a decrease in the reduction in area for all $500^{\circ} \mathrm{F}$ tests, compared to both roomtemperature and $1000^{\circ} \mathrm{F}$ tests, was observed.

Table 1

Chemical analysis results for the Class A wheel steel

\begin{tabular}{c|c|c|c|c|c}
\multirow{2}{*}{ Sample ID } & \multicolumn{5}{|c}{ Element (Weight Percent) } \\
\hline 0 & $\mathbf{C}$ & $\mathbf{M n}$ & $\mathbf{P}$ & $\mathbf{S}$ & $\mathbf{S i}$ \\
\hline 1 & 0.51 & 0.68 & 0.019 & 0.019 & 0.26 \\
\cline { 2 - 6 } & 0.51 & 0.68 & 0.019 & 0.020 & 0.27 \\
\hline $\begin{array}{c}\text { Minimum [9] } \\
\text { Maximum [9] }\end{array}$ & 0.47 & 0.60 & & & 0.15 \\
\cline { 2 - 6 } & 0.57 & 0.85 & 0.050 & 0.050 &
\end{tabular}

Table 2

Average tensile results for the Class A wheel steel at room and elevated temperature

\begin{tabular}{c|c|c|c|c} 
Temp $\left({ }^{\circ} \mathbf{F}\right)$ & $\sigma_{\text {UTS }}, \mathbf{k s i}$ & $\sigma_{\mathbf{Y S}}, \mathbf{k s i}$ & $\boldsymbol{\varepsilon}, \boldsymbol{\%}$ & $\mathbf{R A}, \boldsymbol{\%}$ \\
\hline \multirow{2}{*}{ R.T. } & 134.3 & 90.1 & 15.5 & 32.3 \\
\cline { 2 - 5 } & $125-160^{*}$ & & & \\
\hline 500 & 145.4 & 87.3 & 14.0 & 15.9 \\
\hline 1000 & 69.9 & 56.8 & 19.0 & 56.1
\end{tabular}

* Reference [1] Class A baseline.

\section{Fatigue Test Results}

A summary graph for all fatigue tests at each of the three temperatures and four R-ratios is shown in Fig. 4. To highlight better the differences at each of the three temperatures, graphical summaries of the fatigue data for room temperature, $500^{\circ} \mathrm{F}$, and $1000^{\circ} \mathrm{F}$ are provided in Figs. 5 to 7 , respectively. For each graph cycles to failure are given as a function of actual stress range, which includes the stress concentration effect $\left(\mathrm{K}_{\mathrm{t}}=1.05\right)$. Limited fatigue data is shown for a temperature of $500^{\circ} \mathrm{F}$ as this testing was on-going at the time of final paper submission As expected, a certain degree of scatter in fatigue results is shown for each particular stress range, with the highest amount of scatter at the lower stress levels and therefore the higher life regime. 


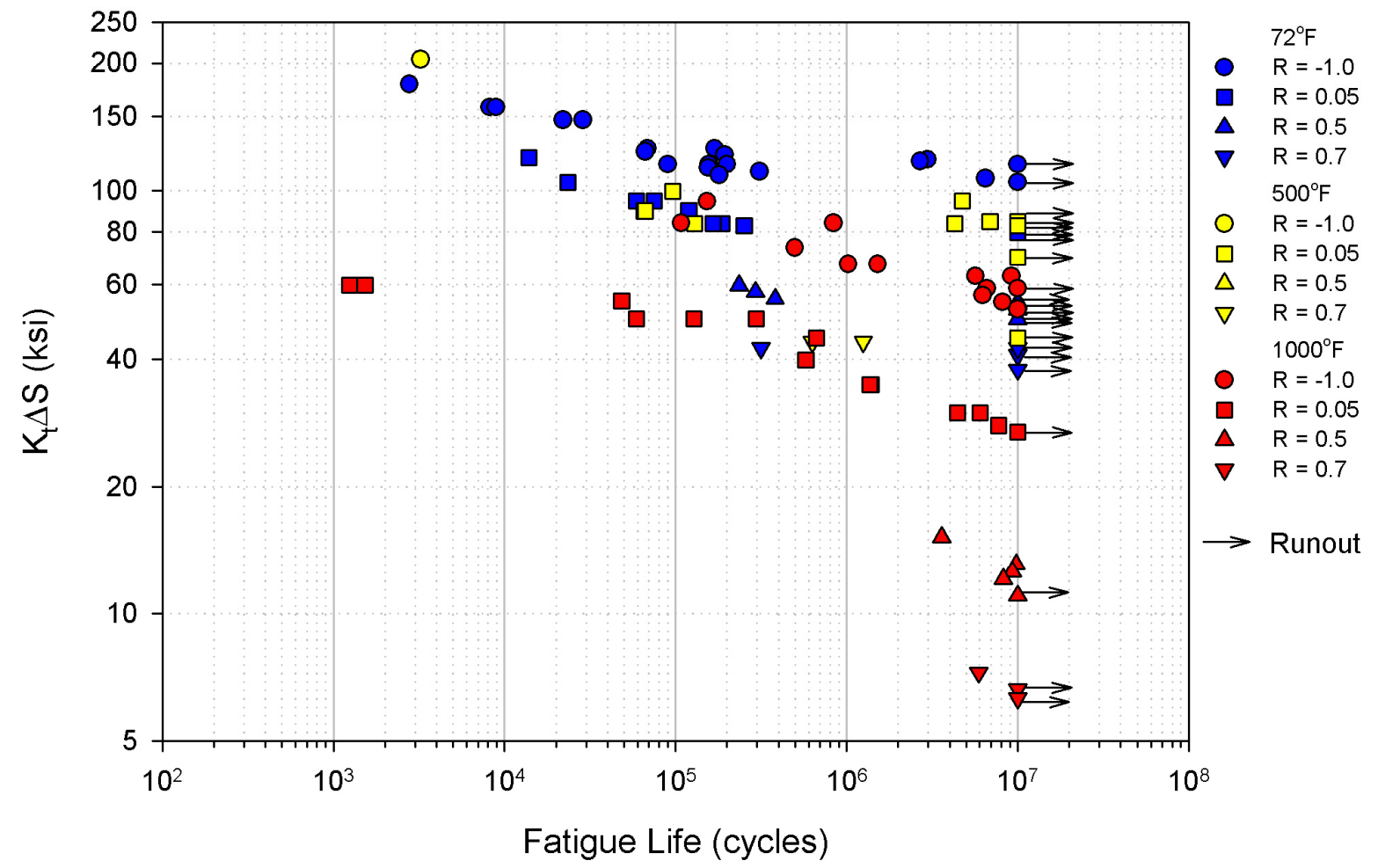

Figure 4

Summary of all fatigue tests performed during test program

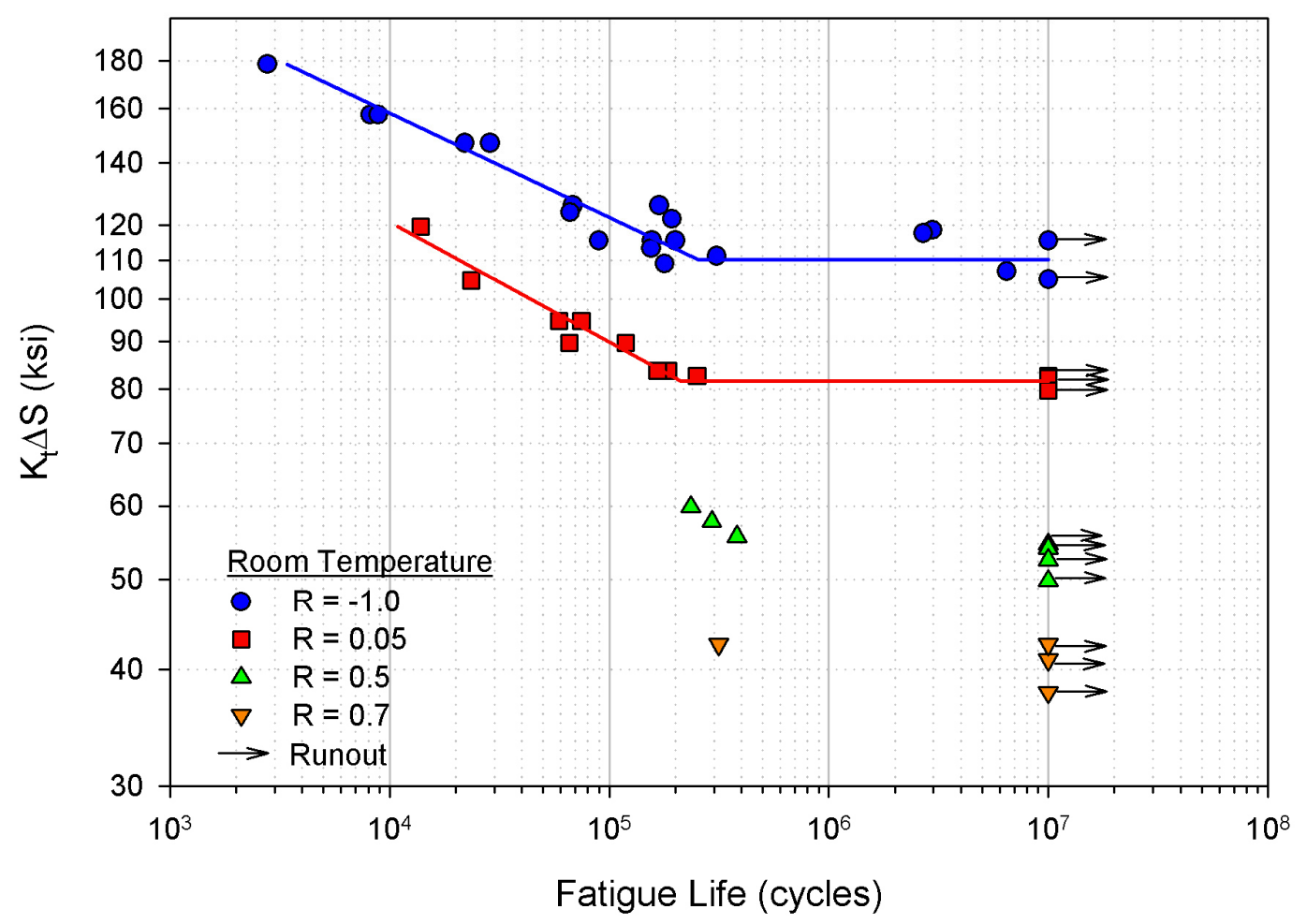

Figure 5

Fatigue test results at room temperature for the Class A wheel steel 


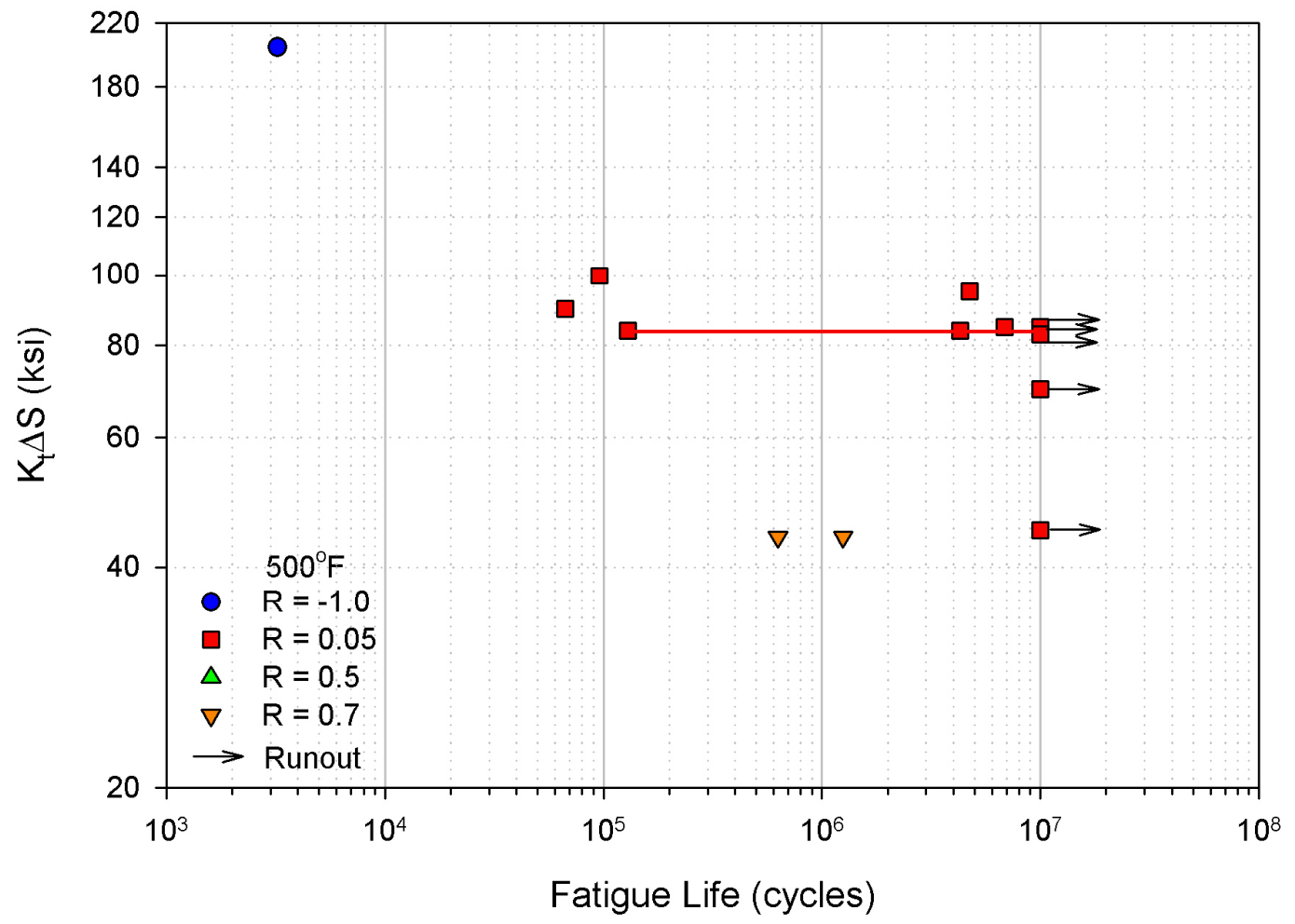

Figure 6

Fatigue test results at $500^{\circ} \mathrm{F}$ for the Class A wheel steel

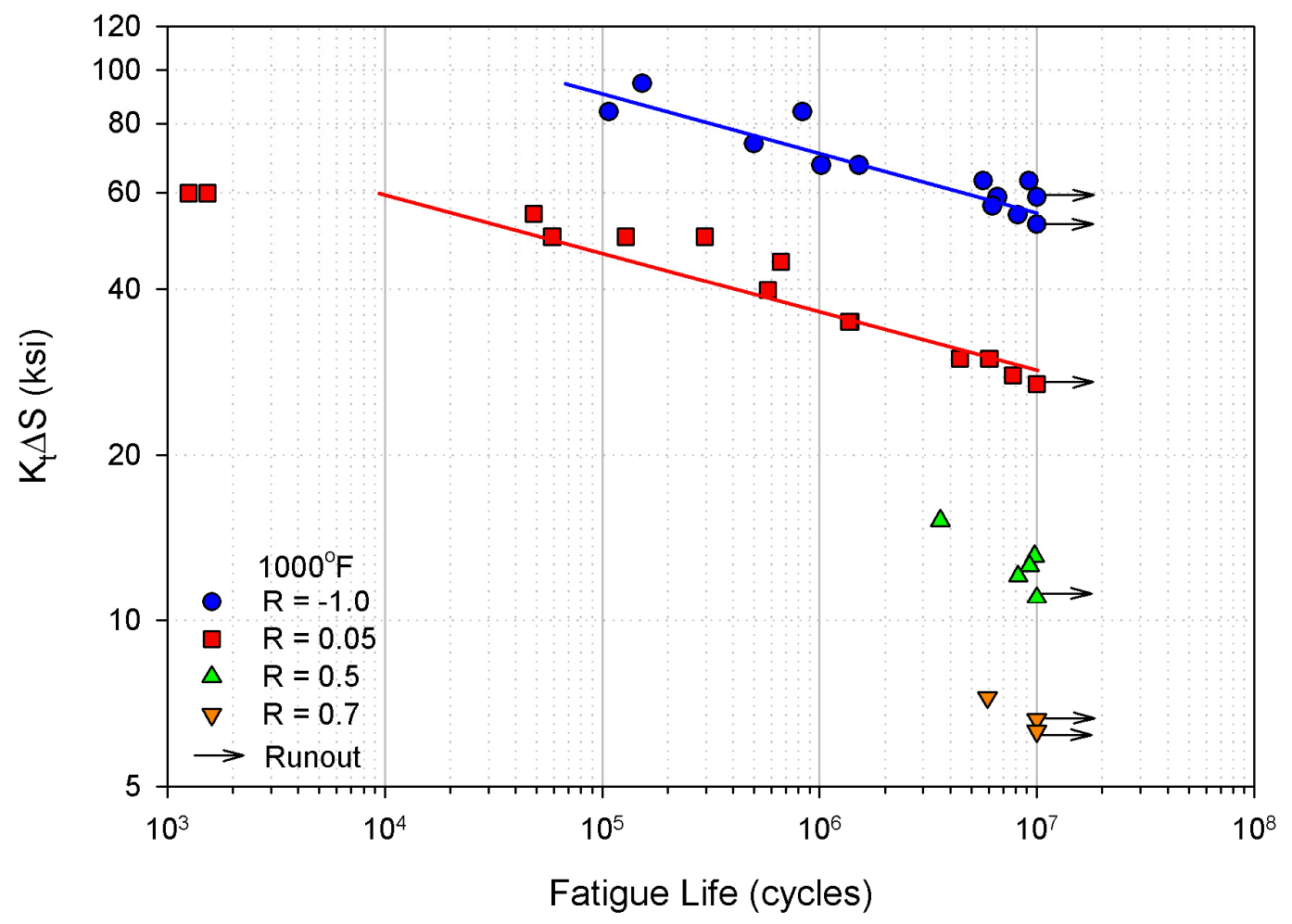

Figure 7

Fatigue test results at $1000^{\circ} \mathrm{F}$ for the Class A wheel steel 
Also provided on each of the summary plots are regression curve fits for the data at the lower R-ratios of $\mathrm{R}=-1.0$ and 0.05 . Due to the limited amount of testing at the higher R-ratios of $\mathrm{R}=0.5$ and 0.7 , only the fatigue life at the $10^{7}$ life regime, termed the endurance limit, was obtained. To obtain the curves shown in Figs. 5 to 7, a simple linear regression on the fatigue data, up to and including the $10^{6}$ life regime, was performed (power law functions are given in Table 3). In this case the independent and dependent variables were $\mathrm{N}$ and $\Delta \mathrm{S}$, respectively. A horizontal line, corresponding to an average stress level for all runout data, was then extended out to the $10^{7}$ life regime. It is interesting to note that for the $1000^{\circ} \mathrm{F}$ hightemperature tests, there did not appear to be the usual endurance limit transition at the lower stress levels, for each Rratio, as was found with the room-temperature and $500^{\circ} \mathrm{F}$ tests.

Due to the large amount of data produced in this fatigue test program, over a wide variety of R-ratios, it is possible to develop the endurance limit diagram for the three test temperatures. Endurance limit diagrams for the roomtemperature, $500^{\circ} \mathrm{F}$, and $1000^{\circ} \mathrm{F}$ tests are shown together for comparison in Fig. 8. The vast difference in tensile strength properties when testing at $1000^{\circ} \mathrm{F}$ is indicative of the subsequent detrimental effect on the endurance limit diagram at this temperature.

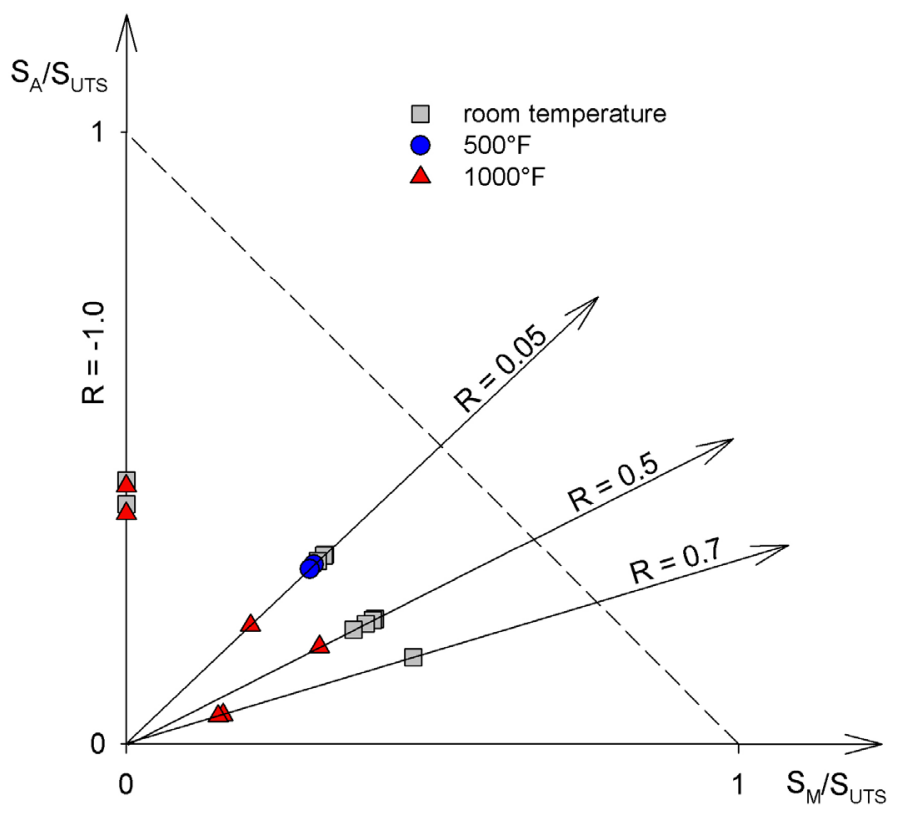

Figure 8

Endurance limit diagram for the Class A wheel steel at all test temperatures

Photographs of two typical fracture surfaces are shown in Fig. 9 illustrating both surface and sub-surface initiation sites. These modes were observed for all test temperatures and there did not appear to be any preferential initiation site at the point where the thermocouple was in contact with the specimen during high-temperature testing.
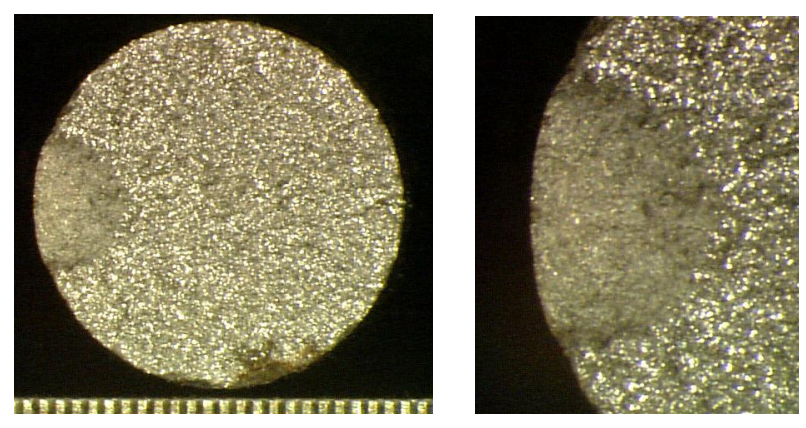

(a)
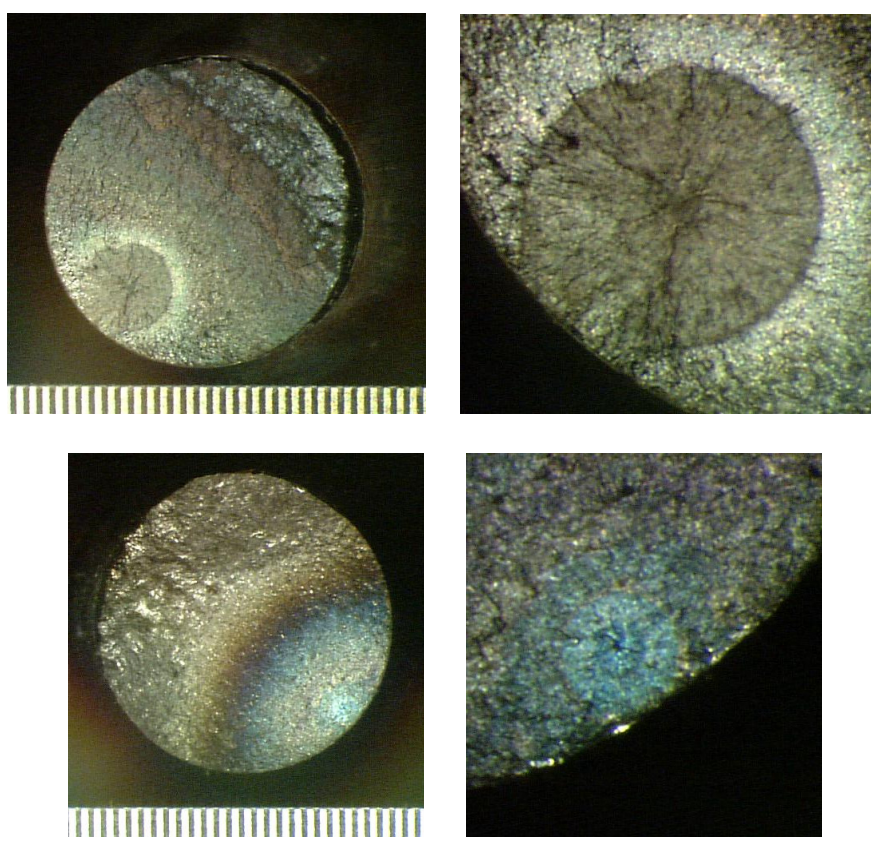

(b)

Figure 9

Examples of (a) surface and (b) subsurface crack initiation observed in specimens (scale division $=0.01$ inch)

\section{Estimation of Sines Parameters}

Based on the results given in the previous section it is possible to provide an estimation of the Sines parameters, A and $\alpha$, for the $10^{7}$ life regime. Endurance limit data at the $10^{7}$ life regime, for R-ratios $=-1.0$ and 0.05 , is required to calculate the two material constants (see section on Data Analysis). Using Eqs. (3) and (5) the constants A and $\alpha$ were estimated with results provided in Table 4.

The Sines parameters for the $1000^{\circ} \mathrm{F}$ fatigue tests are dramatically different from those of the lower temperature fatigue tests. This is not surprising considering the large difference in both tensile and fatigue properties obtained for the $1000^{\circ} \mathrm{F}$ tests, when compared to the room-temperature tests. 
Table 3

Regression analysis of fatigue data for each of the three test temperatures

\begin{tabular}{|c|c|c|c|c|c|}
\hline $\operatorname{Temp}\left({ }^{\circ} \mathbf{F}\right)$ & R-ratio & Stress Range, $\Delta \mathbf{S}$ (ksi) & $\begin{array}{c}\text { Power La } \\
\text { A }\end{array}$ & $\begin{array}{c}\text { stants } \\
\text { b }\end{array}$ & Cycles to Failure \\
\hline \multirow{2}{*}{ R.T. } & -1.0 & $\begin{array}{l}>110.3 \\
\leq 110.3\end{array}$ & $4.753 \times 10^{23}$ & -8.946 & $\begin{array}{c}N=A \Delta S^{b} \\
\text { Runout }\end{array}$ \\
\hline & 0.05 & $\begin{array}{l}>81.6 \\
\leq 81.6\end{array}$ & $1.291 \times 10^{20}$ & -7.734 & $\begin{array}{c}N=A \Delta S^{b} \\
\text { Runout }\end{array}$ \\
\hline \multirow{2}{*}{1000} & -1.0 & $\geq 55.7$ & $1.666 \times 10^{21}$ & -8.171 & $N=A \Delta S^{b}$ \\
\hline & 0.05 & $\geq 26.9$ & $4.570 \times 10^{20}$ & -9.388 & $N=A \Delta S^{b}$ \\
\hline
\end{tabular}

Table 4

Sines criterion material constant estimates for the three test temperatures

\begin{tabular}{|c|c|c|c|c|c|}
\hline \multirow[b]{3}{*}{$\operatorname{Temp}\left({ }^{\circ} \mathbf{F}\right)$} & \multirow[b]{3}{*}{ R-ratio } & \multicolumn{4}{|c|}{ Sines Constants at Endurance Limit (10 ${ }^{7}$ Life Regime) } \\
\hline & & \multicolumn{2}{|c|}{ Stress Amplitude (ksi) } & \multirow[b]{2}{*}{$\mathbf{A}(\mathbf{k s i})$} & \multirow[b]{2}{*}{$\alpha$} \\
\hline & & $f_{1}$ & $f_{1}^{\prime}$ & & \\
\hline \multirow{2}{*}{ R.T. } & -1.0 & 55.1 & & \multirow{2}{*}{26.0} & \multirow{2}{*}{0.165} \\
\hline & 0.05 & & 40.8 & & \\
\hline \multirow{2}{*}{1000} & -1.0 & 27.8 & & \multirow{2}{*}{13.1} & \multirow{2}{*}{0.499} \\
\hline & 0.05 & & 13.5 & & \\
\hline
\end{tabular}




\section{CONCLUDING REMARKS}

The material property evaluations described herein provide an assessment of the chemical, tensile, and fatigue behavior observed for the Class A wheel steel material. Fatigue testing was performed to determine the S-N curves for each of the three temperatures, $72^{\circ} \mathrm{F}, 500^{\circ} \mathrm{F}$, and $1000^{\circ} \mathrm{F}$. Furthermore, a large number of fatigue tests were performed at R-ratios of -1.0 and 0.05 for each of the test temperatures to enable reliable estimates of the Sines parameters, A and $\alpha$. Chemical, tensile, and fatigue results can be briefly summarized with major conclusions indicated below.

1. Very similar ultimate tensile strength and yield strength results were found for the room-temperature and $500^{\circ} \mathrm{F}$ tests. However, a greater than $47 \%$ reduction in ultimate tensile strength and $36 \%$ reduction in yield strength were observed for the $1000^{\circ} \mathrm{F}$ tensile tests, when compared to both the roomtemperature and $500^{\circ} \mathrm{F}$ tests.

2. A large decrease in the reduction in area for all $500^{\circ} \mathrm{F}$ tests, compared to both room-temperature and $1000^{\circ} \mathrm{F}$ tests, was observed. As the tensile specimens were randomly selected from both railroad wheels, for each of the three temperatures, it is unlikely that the difference is a consequence of material variation in one specific wheel.

3. A total of 92 constant amplitude fatigue tests were completed at the three test temperatures. The vast majority of testing $(70 \%)$ was performed at R-ratios of -1.0 and 0.05 to enable the S-N curves to be developed. The remainder of testing was undertaken to obtain the endurance limit at $10^{7}$ cycles for R-ratios of 0.5 and 0.7 .

4. The degree of scatter for fatigue tests averaged approximately one order of magnitude (10x) for all tests performed at replicate stress levels, with a scatter range of between $1.08 \mathrm{x}-111 \mathrm{x}$. As expected, greater levels of scatter and less repeatability were apparent at the lower stress levels.

5. Fracture surfaces indicated both surface and sub-surface initiation sites under all test temperatures. The thermocouple position during high-temperature testing did not appear to provide a preferential initiation site.

6. Endurance limit data was obtained for all R-ratios at each of the three test temperatures. However, for the $1000^{\circ} \mathrm{F}$ tests there did not appear to be the usual endurance limit transition at the lower stress levels, as was found with the roomtemperature and $500^{\circ} \mathrm{F}$ tests. Endurance limit diagrams for the three test temperatures were constructed.

7. Based on the endurance limit data for R-ratios of -1.0 and 0.05 , an estimation of the Sines parameters, A and $\alpha$, was obtained for room temperature and $1000^{\circ}$ F. Significantly different parameters were obtained for the $1000^{\circ} \mathrm{F}$ fatigue tests.

\section{ACKNOWLEDGMENTS}

This work was carried out under the Rail Equipment Safety program sponsored by the Office of Research and Development, Federal Railroad Administration, U.S. Department of Transportation, under the direction of Ms. Claire L. Orth, Chief, Equipment and Operating Practices Research Division. Ms. Monique Stewart is the Project Manager for the research related to railroad wheel safety. Gratitude is expressed to Ms. Susan McDonough (FosterMiller) for overseeing this subcontract. Appreciation is further extended to Cameron Lonsdale (Standard Steel) for his efforts in procuring the wheels used herein. Thomas Luna, Ernest Montelongo, Ryan Whitaker, and Forrest Campbell all assisted in performing this testing. Finally, thanks to Loretta Mesa for patiently preparing this manuscript.

\section{REFERENCES}

[1] Association of American Railroads, Standard S-660, "Procedure for the Analytic Evaluation of Locomotive and Freight Car Wheel Designs," Manual of Standards and Recommended Practices, Section G, Wheels and Axles, 2004.

[2] Sines, G., 1959, "Behavior of Metals Under Complex Static and Alternating Stresses," Metal Fatigue, G. Sines and J. L. Waisman, Eds., McGraw-Hill, NY, pp.145-169.

[3] "Homologation Technique des Roues Monobloc," 1998, UIC Minutes, MTEL P 98016.

[4] Gordon, J. E. and Orringer, O., 1994, "Investigation of the Effects of Braking System Configurations on Thermal Input to Commuter Car Wheels," Volpe National Transportation Systems Center, Cambridge, MA, Report No. DOT/FRA/ORD-94-01.

[5] McKeighan, P. C., McMaster, F. J., and Gordon, J., "Fatigue Performance of AAR Class B Railroad Wheel Steel at Ambient and Elevated Temperatures," ASME International Mechanical Engineering Congress and Exposition, 17-22 November 2002, New Orleans, LA.

[6] Annual Book of ASTM Standards, Section 3: Metals Test Methods and Analytical Procedures, Vol. 3.01 Metals Mechanical Testing; Elevated and Low-Temperature Tests; Metallography, 2000.

[7] ASTM E1019-00, "Standard Test Methods for Determination of Carbon, Sulfur, Nitrogen, and Oxygen in Steel and in Iron, Nickel, and Cobalt Alloys," Annual Book of ASTM Standards, Section 3: Metals Test Methods and Analytical Procedures, Vol. 3.05, American Society for Testing and Materials, West Conshohocken, PA.

[8] ASTM E415-99a, "Standard Test Method for Optical Emission Vacuum Spectrometric Analysis of Carbon and Low-Alloy Steel," Annual Book of ASTM Standards, Section 3: Metals Test Methods and Analytical Procedures, Vol. 3.05, American Society for Testing and Materials, West Conshohocken, PA.

[9] Association of American Railroads, Specification M107/208, "Wheels, Carbon Steel," Manual of Standards and Recommended Practices, Section G, Wheels and Axles, 2004. 